\title{
Effects of ulinastatin and docetaxel on breast cancer invasion and expression of UPA, UPAR and ERK
}

\author{
Jie Luo, Xin Sun, Feng Gao, Xiaoliang Zhao, Biao Zhong, Hong Wang and Zhijun Sun ${ }^{*}$
}

\begin{abstract}
Objective: To investigate the effects of ulinastatin and docetaxel on invasion of breast cancer cells and expression of UPA, UPAR and ERK, breast cancer MDA-MB-231 and MCF-7 cells.

Methods: The nude mice were treated with PBS, ulinastatin, docetaxel, and ulinastatin plus docetaxel, respectively. Their effects on 1) cell invasion ability was assayed using Transwell; 2) expression of UPA, UPAR and ERK was detected by real time PCR and Western blot; 3) UPA, UPAR and p-ERK protein level in nude mice was quantified by immunohistochemistry.
\end{abstract}

Results: 1) Treatment with ulinastatin, docetaxel, and ulinastatin plus docetaxel, respectively, significantly inhibited MDA-MB-231 and MCF-7 cell invasion; 2) mRNA and protein levels of UPA, UPAR and ERK1/2 were inhibited by ulinastatin, but enhanced by docetaxel.

Conclusion: Ulinastatin can enhance the effects of docetaxel on invasion of breast cancer cells. And that UPA, UPAR and p-ERK expression is obviously inhibited by ulinastatin.

\section{Introduction}

Breast cancer is one of the major malignant tumors threaten women well being. Failure in its treatment mainly arises from cancer proliferation, invasion and metastasis, which ultimately lead to the death of patients. Cell penetrating into extracellular base membrane is the premise of cancer cell metastasis, where a variety of proteases play essential roles.

Plasminogen activators (PAs) are serine proteases, the main function of which is to activate plasminogen into plasmin, a serine protease that hydrolyzes a variety of proteins, including laminin, fibronectin, fibrin, proteoglycan core protein and collagen fibres. There are two types of mammalian PAs: tissue-type (tPA) and urokinase-type (uPA). The former is mainly present in circulatory system, while the latter is present in cells and closely related to tumor cell invasion and metastasis. It has been shown that UPA expression is enhanced in many malignant tumors, such as breast cancer, prostate

\footnotetext{
* Correspondence: cq_sunzj@sina.com Department of Breast, Pancreas, and Thyroid Surgery; Second Affiliated Hospital of Chongqing Medical University, 74 Lingjiang Road, Yuzhong District, Chongqing 400010, China
}

(c) 2011 Luo et al.; licensee BioMed Central Ltd. This is an open access article distributed under the terms of the Creative Commons Attribution License (http://creativecommons.org/licenses/by/2.0), which permits unrestricted use, distribution, and reproduction in any medium, provided the original work is properly cited. on its receptor uPAR in cells. In breast cancer, uPAuPAR complex is necessary to maintain and amplify plasmin activity[1].

Beside its pivotal roles in pasminogen cascade system, uPA-uPAR complex can also activate many signaling pathways, of which is important Ras-Raf-MEK-ERK pathway. This pathway responds to signals from a variety of growth factors (EGF, NGF, PDGF, etc.), mitogens and environmental stimulations, eventually leading to activation and phosphorylation of extracellular signalregulated kinase (ERK) through the signal amplification cascade. Phosphorylated ERK translocates to nucleus, where it acts on the AP-1, NF- $\kappa \mathrm{B}$ and other nuclear transcription factors, thereby regulating gene expression and promoting tumor cell proliferation, differentiation and survival. Over-activation of ERK has been found in many human malignant tumors including oral cancer, melanoma and breast cancer[2,3].

Urinary trypsin inhibitor ulinastatin as a broad-spectrum protease inhibitor can inhibit trypsin, chymotrypsin, plasmin, human leukocyte elastase and cancer, colon cancer, stomach cancer and lung cancer, 
hyaluronidase. It has anti-tumor metastasis and protective effects on patients accepted radiotherapy and chemotherapy and been widely used to treat acute pancreatitis and shock and to improve surgical outcome in clinic. Ulinastatin can bind to tumor cells through its $\mathrm{N}$-terminal Domain I and exert its inhibitory effect on proteolytic activity of plasmin by binding to tumor cells through its C-terminal domain II, the major anti-fibrinolytic group. The impact of ulinastatin on uPA is more complicated. In addition to its inhibitory effects on gene transcription, it also inhibits uPA protein expression by affecting kinase $\mathrm{C}$ and MEK/ERK/c-Jun signaling pathways[4,5].

To find a more effective treatment for breast cancer, this study explored the additive effects of docetaxel and ulinastatin on the proliferation of breast cancer MDAMB-231 cells and tumor growth in nude mice.

\section{Materials and methods}

\section{Materials}

Ulinastatin was purchased from Guangdong Techpool Bio-Pharma Co., Ltd. Docetaxel was bought from Sanofi-Aventis (French). SYBR Green/ROX qPCR Master Mix (2X) were purchased from Fermentas Inc. (Canada). Anti-uPA antibody was from Bioworld (USA). Anti-uPAR and anti-pERK antibodies were from Santa Cruz (USA). 24 well Transwell plates were from Corning (USA). Matrigel was from BD Company (USA).

\section{Cell culture}

Human breast cancer cell line MDA-MB-231 (ER-) and MCF-7 (ER+) were kindly gifted by Shanghai Institute of Biological Sciences, Chinese Academy of Sciences, and maintained in RPMI-1640 medium supplemented with $10 \%$ fetal bovine serum, $100 \mathrm{U} / \mathrm{mL}$ penicillin, 100 $\mathrm{mg} / \mathrm{L}$ streptomycin at $37^{\circ} \mathrm{C}$ in an incubator supplemented with $5 \% \mathrm{CO}_{2}$ under saturated humidity.

\section{Animals}

100 female BALB/c (nunu) mice at age 4-6 weeks and with body weight of 17-21 g from Animal Research Center of Chongqing Medical University (Production License No.: SCXK (Beijing) 2005-0013, the use permit number: SYX (Chongqing) 2007-0001) were kept in SPF-class environment at $22-25^{\circ} \mathrm{C}$ and $50-65 \%$ humidity. Drinking water, feed and experimental materials were sterilized and all experiments were complied with sterile principle.

\section{Animal experiments}

MDA-MB-231 cells at logarithmic growth phase were washed twice with PBS and prepared as $2.5 \times 10^{10}$ cells/ $\mathrm{L}$ suspension in serum-free RPMI-1640 medium. $0.2 \mathrm{~mL}$ cell suspension was subcutaneously inoculated in the right armpit of each mouse. 21 days after inoculation, 29 out of 50 mice had tumor volume $\geq 500 \mathrm{~mm}^{3}$ and randomly assigned into 4 groups[6]. MCF-7 cell was innoculated into the other 50 nude mice for building the model[7].

\section{MDA-MB-231 and MCF-7 cell invasion assay}

Breast cancer cell invasion was measured using Transwell chamber. In detail, $2 \times 10^{5}$ cells were placed in the upper chamber of Transwell with a membrane coated with Matrigel. $24 \mathrm{~h}$ later, cells were incubated with 800 $\mathrm{U} / \mathrm{mL}$ ulinastatin, $3.7 \mu \mathrm{g} / \mathrm{mL}$ docetaxel, $800 \mathrm{U} / \mathrm{mL}$ ulinastatin plus $3.7 \mu \mathrm{g} / \mathrm{mL}$ docetaxel, and PBS, respectively, at $37^{\circ} \mathrm{C}$ in an incubator supplemented with $5 \% \mathrm{CO}_{2} .24$ $\mathrm{h}$ later, cells in the upper chamber were removed with a cotton swab. The remaining cells on the membrane were stained with $0.1 \%$ crystal violet solution and washed with PBS. Crystal violet attached to the cells was dissolved by adding $500 \mu \mathrm{L}$ of $33 \%$ acetic acid into the lower chamber and its absorbance at $570 \mathrm{~nm}$ was measured and used to calculate relative amount of cells invaded through the Matrigel to the lower chamber.

\section{MRNA levels of UPA, UPAR and ERK in MDA-MB-231 and MCF-7 cells measured by real-time RT-PCR}

To evaluate the effect of treatments described above on mRNA levels of uPA, uPAR and ERK in breast cancer cells, $24 \mathrm{~h}$ after the treatment, total mRNAs were isolated using $1 \mathrm{~mL}$ TRIzol reagent according to the protocol provided by the manufacturer. $20 \mu \mathrm{L}$ mRNA was reverse transcripted into cDNA and the amount of uPA, UPAR and ERK cDNA was examined by quantitative real-time PCR using the following primer pairs: $u P A$ forward primer 5'-GGAGATGAAGTTTGAGGT-GG-3' and reverse primer 5'-GGTCTGTATAGTCCGGGATG-3', uPAR forward primer

5'-CACAAAACTGCCTCCTTCCT-3' and reverse primer

5'-AATCCCCGTTGGTCTTACAC-3', ERK forward primer

5'-CCTAAGGAAAAG-CTCAAAGA-3' and reverse primer

5'-AAAGTGGATAA-GCCAAGAC-3', and $\beta$-actin forward primer

5'-GCAGAAGGAGATCACAGCCCT-3' and reverse primer

5'-GCTGATCCACATCTGCTGGAA-3'. The corresponding predicted products were $142,178,180$, and $136 \mathrm{bp}$, respectively. In detail, template cDNA and primers were mixed with SYBR Green/ROX qPCR Master Mix (2X) in $25 \mu \mathrm{L}$ reaction system and PCR was carried out in triplicate under the following conditions: $5 \mathrm{~min}$ at $95^{\circ} \mathrm{C}, 45$ cycles of 15 seconds at $95^{\circ} \mathrm{C}$ and 30 seconds at $60^{\circ} \mathrm{C}, 1 \mathrm{~min}$ at $95^{\circ} \mathrm{C}$ and 1 minute at $55^{\circ} \mathrm{C}$. Ct value 
of each sample was defined as cycle number when the fluorescence intensity reached the threshold. Relative RNA level was normalized to $\beta$-actin and quantified using $2^{-\Delta \Delta}$.

\section{Protein expression of UPA, uPAR and p-ERK $1 / 2$ determined by Western blot}

$24 \mathrm{~h}$ after treated as described above, MDA-MB-231 cells were lysed with $25 \mu \mathrm{L}$ buffer and mixed with $2 \times$ sample buffer. Proteins were then subjected to SDSPAGE and transferred onto PVDF membrane. The membrane was incubated overnight with primary antibodies against UPA, UPAR and p-ERK1/2, respectively, at $4^{\circ} \mathrm{C}$ and subsequently with secondary antibodies for 1 hour. After wash with PBST, signals were visualized by incubation with ECL luminescence substrate and detected with Universal Hood2 Chem GelDocxR Gel Imaging System (Bio-Rad, USA).

\section{Expression of UPA, UPAR and $p$-ERK $1 / 2$ in mouse xenografts by immunohistochemistry SP method} uPA, uPAR and p-ERK1/2 in slides of collected mouse xenografts were labeled with antibodies against uPA, uPAR and p-ERK1/2, respectively, followed by incubation with corresponding secondary antibodies. The labeled proteins were visualized with DAB reagent and examined under microscope. Cells with brown or brownish yellow granules were considered as positive and analyzed using Image Pro-plus 6.0 image analysis software to calculate integrated optical density (IOD).

\section{Statistical analysis}

All data were expressed as mean $\pm \mathrm{s}$ and analyzed using statistical analysis software SPSS 18.0. Differences between groups were tested using analysis of variance. A $p$ value less than 0.05 was considered as statistical significance.

\section{Results}

1. Effects of ulinastatin and docetaxel on MDA-MB-231 and MCF-7 cells invasion

Absorbance value at $570 \mathrm{~nm}$ reflects the number of cells penetrated the Matrigel and membrane of the Transwell. As shown in Figure 1, the invasion rates of cells treated with ulinastatin, docetaxel and ulinastatin plus docetaxel were $20.861 \%, 35.789 \%$ and $52.823 \%$, respectively, all significantly decreased compared with that of the control $(\mathrm{p}<0.01)$.

\section{Effects of ulinastatin and docetaxel on UPA, UPAR and ERK mRNA level}

As shown in Figure 2(1), uPA and UPAR mRNA levels in MDA-MB-231cells treated with ulinastatin as well as ulinastatin plus docetaxel were significantly decreased compared with those in control treated cells $(\mathrm{p}<0.05)$.

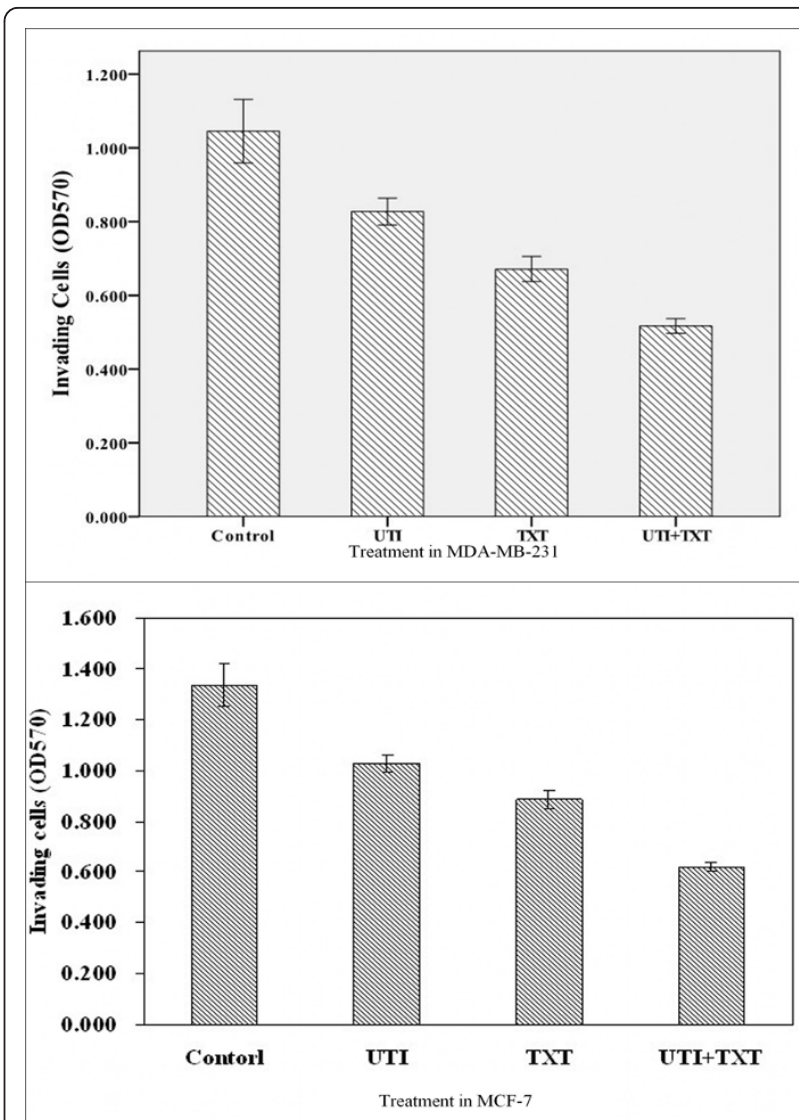

Figure 1 Inhibition of ulinastatin and docetaxel on MDA-MB231 and MCF-7 cell invasion. Shown are the absorptions at 570 $\mathrm{nm}$ of cells treated with ulinastatin, docetaxe and ulinastatin plus docetaxe for 24 hours, respectively, in the lower chambers of transwells. Treatment of cells with ulinastatin, docetaxe and ulinastatin plus docetaxe significantly inhibited MDA-MB-231(1a) and MCF-7 (1b) cell invasion.

By contrast, uPA and UPAR mRNA levels were significantly enhanced in cells treated with docetaxel ( $\mathrm{p}<$ 0.05). In addition, all treatments had no effects on ERK mRNA level $(\mathrm{p}=0.9)$. However, ERK mRNA has statistical difference in MCF-7 ( $\mathrm{p}<0.05)$. Figure $2(2)$.

\section{Effects of ulinastatin and docetaxel on UPA, UPAR and phosphorylated ERK1/2 (p-ERK1/2) proteins}

Levels of UPA, uPAR and p-ERK1/2 in MDA-MB-231 cells treated with ulinastatin and docetaxel are shown in Figure 3(1). Treatment of cells with ulinastatin alone or along with docetaxel significantly decreased uPA, UPAR and p-ERK1/2 level in MDA-MB-231 cells. By contrast, treatment of cells with docetaxel significantly augmented uPA, uPAR and p-ERK1/2 levels Figure 3(2) $(\mathrm{p}<0.05)$.

4. UPA, UPAR and $p$-ERK $1 / 2$ level in exograft of nude mice Specimens of MDA-MB-231 mouse exografts were immunostained for $\mathrm{UPA}, \mathrm{UPAR}$ and $\mathrm{p}$-ERK. The IOD 


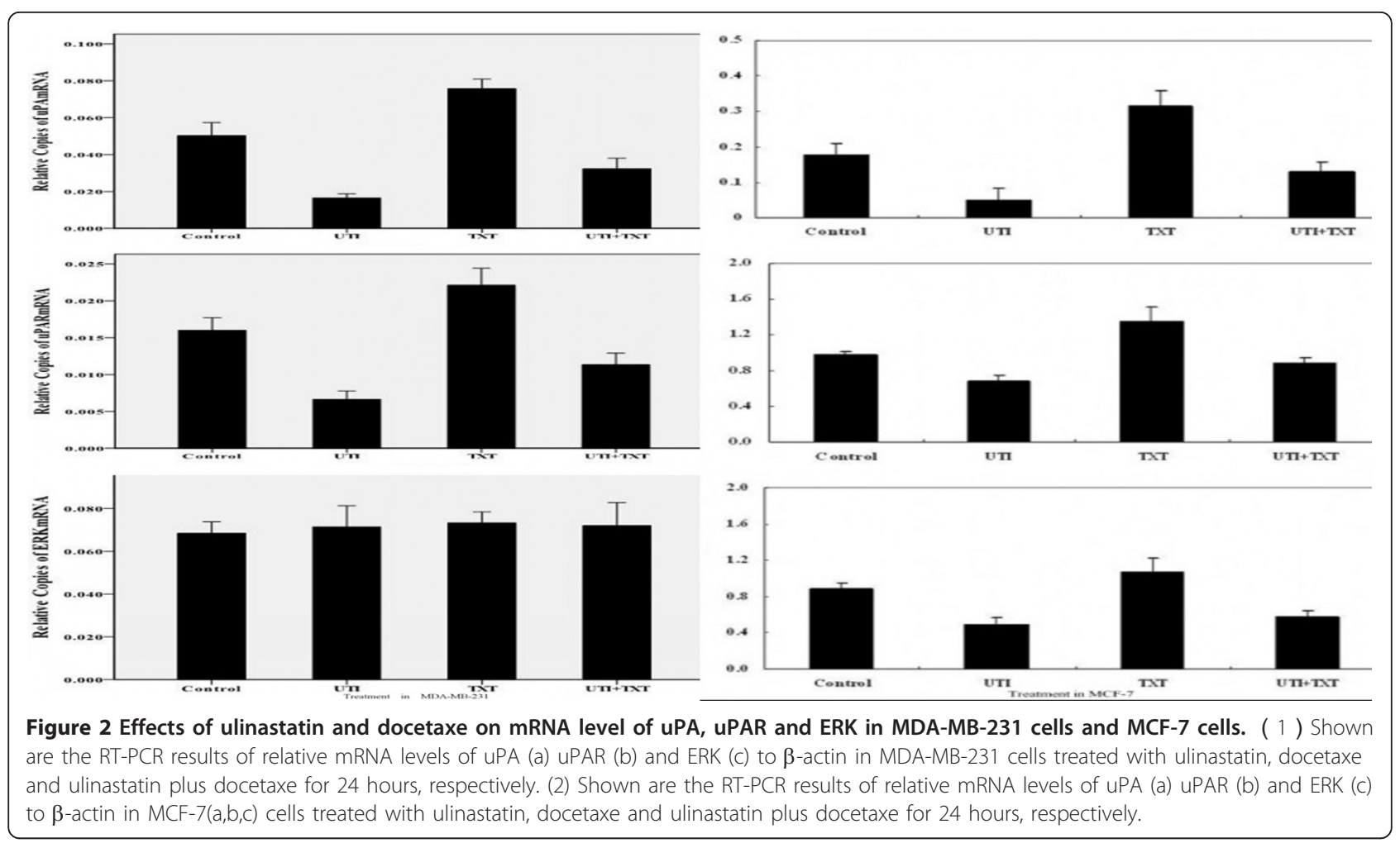

values of the targeted proteins in each group were statistically analyzed. The levels of uPA, uPAR and p-ERK1/2 in ulinastatin group were lower than those of ulinastatin plus docetaxel group; both groups had significant lower levels of uPA, uPAR and p-ERK1/2 than the control group. Figure 4,6. By contrast, the levels of uPA, uPAR and $\mathrm{p}$-ERK in docetaxel group were significantly higher than those of the control group ( $\mathrm{p}<0.05)$. The immunohistochemistry result of MCF-7 is same as the result in MDA-MB-231. Figure 5,7.

\section{Discussion}

Proliferation and invasion are important biological features of breast cancer. Because the development of breast cancer involves many extremely complicate regulatory factors, its treatment is often difficult. Therefore, the objective of the study is to explore various cytokines' mechanisms and relationship in regulating tumor cell proliferation and invasion, and eventually find the corresponding optimal therapeutic measures.

Urokinase-type plasminogen activator (uPA) is the hub of the plasminogen activator system, also known as

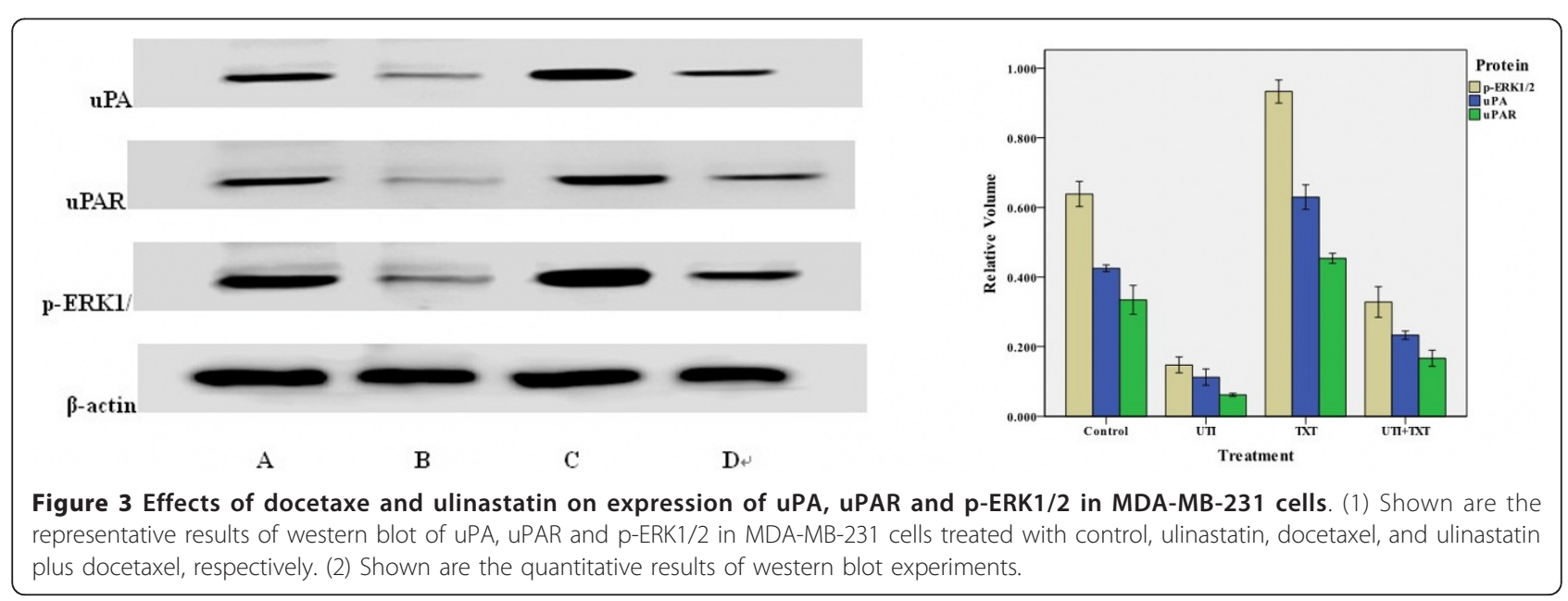




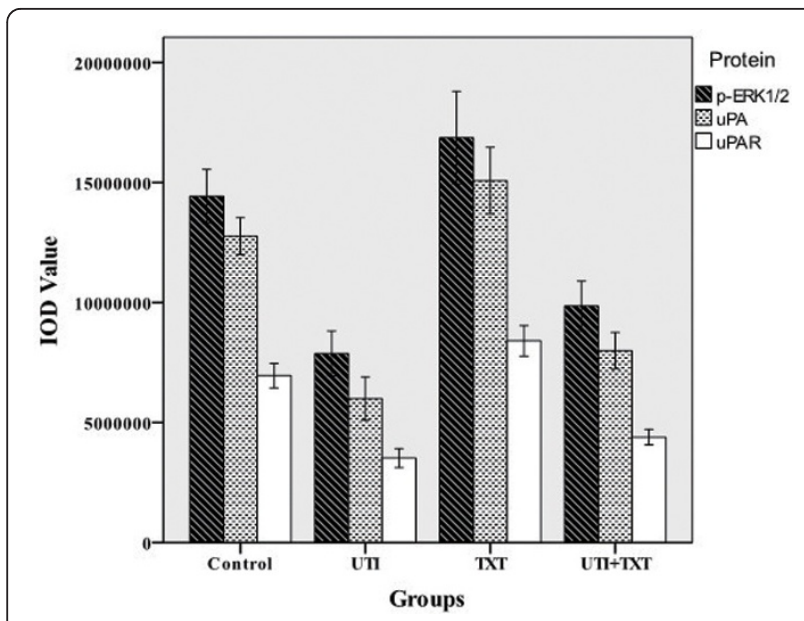

Figure 4 Effects of docetaxe and ulinastatin on expression of uPA, uPAR and p-ERK1/2 in mouse exografts. Shown are the quantitative results of $\mathrm{UPA}, \mathrm{UPAR}$ and $\mathrm{p}$-ERK1/2 expression in exografts of mice treated with control, ulinastatin, docetaxel, and ulinastatin plus docetaxel, respectively, in immunohistochemical experiments.

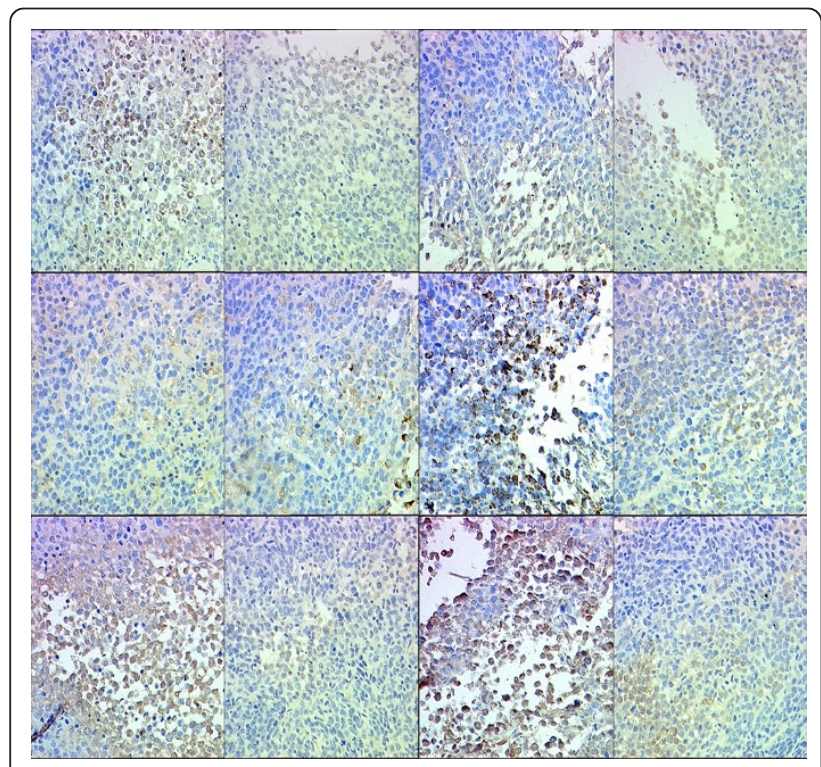

Figure 5 Positive immunohistochemical expression of UPA, uPAR, p-ERK1/2 in MDA-MB-231 exnografts of mice in control (a), ulinastatin(b), docetaxel(c), ulinastatin plus docetaxel(d) groups $(\mathbf{S P}, \times \mathbf{4 0 0})$ (1). Positive immunohistochemical expression of UPA in MDA-MB-231 exnografts of mice in control (a), ulinastatin (b), docetaxel (c), and ulinastatin plus docetaxel (d) groups (SP, $\times 400) .(2)$. Positive immunohistochemical expression of UPAR in MDA-MB-231 exnografts of mice in control (a), ulinastatin (b), docetaxel (c), and ulinastatin plus docetaxel (d) groups (SP, $\times 400)$. (3). Positive immunohistochemical expression of p-ERK1/2 in MDA-MB-231 exnografts of mice in control (a), ulinastatin (b), docetaxel (c), and ulinastatin plus docetaxel (d) groups (SP, $\times 400)$.

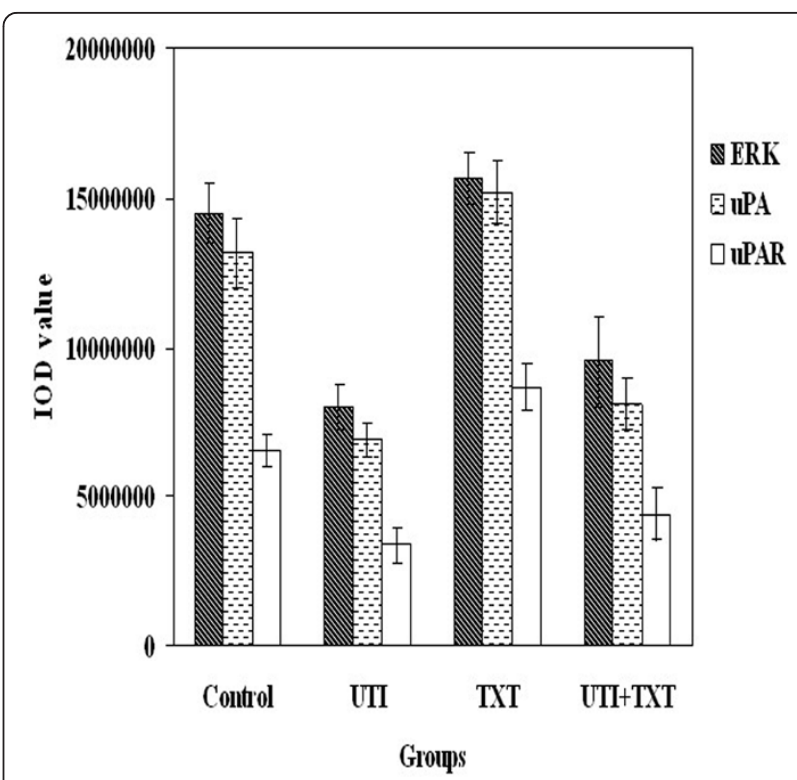

Figure 6 Effects of docetaxe and ulinastatin on expression of uPA, uPAR and p-ERK1/2 in mouse exografts. Shown are the quantitative results of UPA, UPAR and $\mathrm{p}$-ERK1/2 expression in exografts of mice treated with control, ulinastatin, docetaxel, and ulinastatin plus docetaxel, respectively, in immunohistochemical experiments.

uPA system. As a multifunctional serine protease, in addition to its direct contribution to the degradation of extracellular matrix, uPA also mediates activation of matrix metalloproteinase[7], thereby promoting cancer cell invasion and migration. Recent studies have revealed that uPA is involved in angiongenesis and lymphangiogenesis[8] and related to cell proliferation-related signal transduction pathway. Binding of uPA to its receptor UPAR is known to regulate uPAR expression. Therefore, uPA and uPAR usually are similarly over-expressed in breast cancer cells[9].

Ulinastatin binds to cells through its domain I, and exerts its anti-fibrinolytic activity through its domain II. Our results of real time PCR showed that ulinastatin treatment decreased UPA and UPAR mRNA level, suggesting that ulinastatin can inhibit uPA at genetic level and subsequently reducing the expression of UPAR.

ERK belongs to a class of serine/threonine protein kinases found in late 80 s of the last century and is a member of Ras-Raf-MEK-ERK signal transduction pathway. Phosphorylated ERK (p-ERK) can promote cell survival, growth and mitosis by regulating nuclear transcription factor NF- $\kappa \mathrm{B}$ activity. The promoter of uPA gene has NF- $\kappa \mathrm{B}$ binding sites, therefore, p-ERK can increases expression of UPA through activation of NF$\kappa \mathrm{B}[10]$. In addition, a large number of studies in recent 


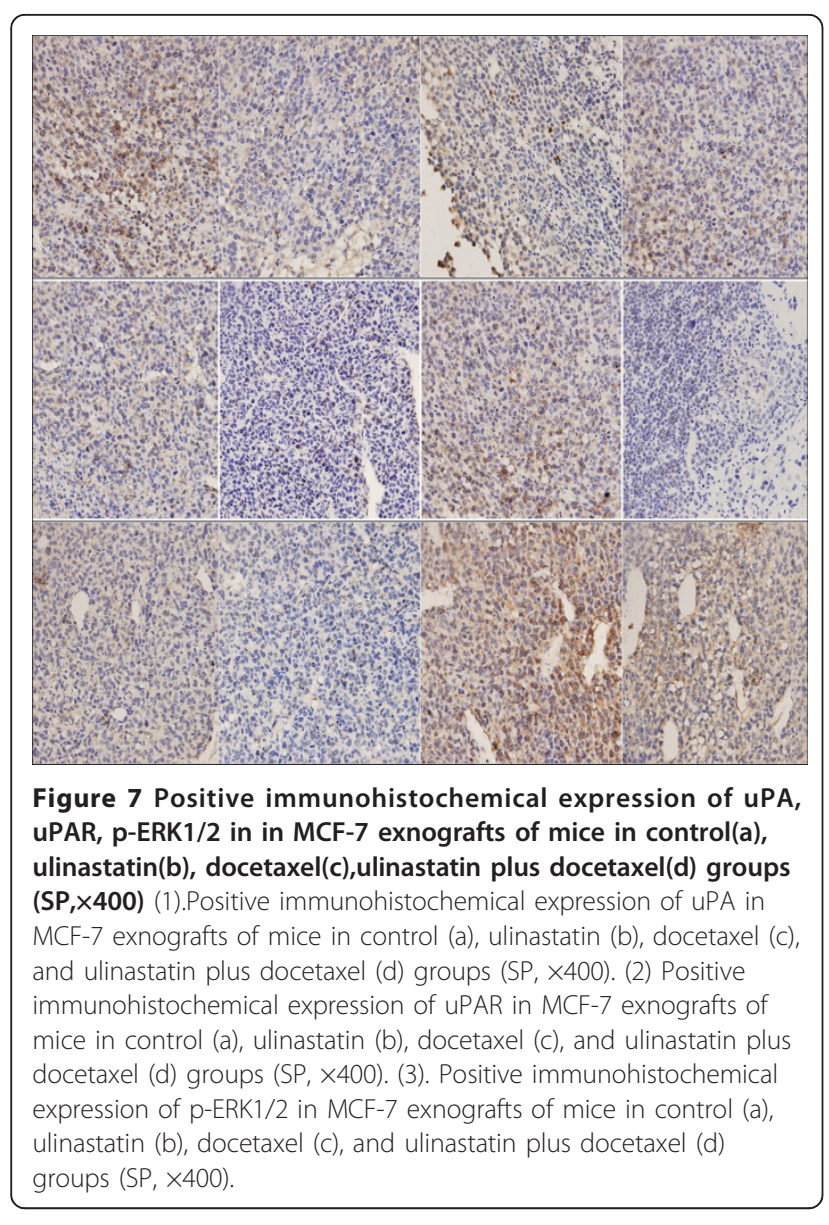

years have confirmed[2,3,11-13] that binding of uPA to uPAR can activate Ras-ERK pathway.

For example, in human breast cancer MCF-7 cells, when the LDL receptor family members are depolymerized, binding of endogenous UPA to UPAR can activate ERK $[14,15]$. The result shows in MCF-7 cells either, its ERK decressed obviously. Furthermore, uPAR can also regulate basal p-ERK level by binding to integrin $\alpha 5 \beta 1$ $[3,16]$. Therefore, uPA-uPAR and ERK can activate each other through different pathways and form a positive feedback loop, thereby maintaining high proliferating and invasive ability of cancer cells.

The basal expression of uPA, uPAR and p-ERK in breast cancer MDA-MB-231 cells are very high[17,18]. Ulinastatin treatment could significantly decrease uPA and uPAR protein expression and mRNA level compared with control group $(\mathrm{p}<0.05)$, possibly due to its inhibitory effect on the translocation of protein kinase $\mathrm{C}$ from the cytoplasm to the membrane and consequent down-regulation of MEK/ERK/c-Jun pathway, thereby causing the decline in uPA expression[5]. its mediateddownregulation of uPA inhibited ERK phosphorylation Figure 4,5,6,7.
Docetaxel can cause cancer cell mitotic arrest at G2/ $M$ phase by inhibiting tubulin depolymerization and promoting non-functional microtube formation. Further studies in recent years have revealed a role of docetaxel in other mechanisms besides cell toxicity. Our experiments also showed that docetaxel treatment increased $\mathrm{p}$-ERK1/2 level $(\mathrm{p}<0.05)$, but decreased uPA and uPAR mRNA and protein levels $(\mathrm{p}<0.05)$, in consistence with the reports of Yacoub and Mhaidat[19,20]. The specific mechanism on how docetaxel functions has not yet been clarified, but probably is related to its role in initiation of cell apoptosis and consequent activation of ERK pathway and p-ERK-dependent upregulation of uPA expression. In addition, reports have shown that pretreatment of cells with other ERK activity specific inhibitor can markedly promote the effect of docetaxel on cell apoptosis[20,21]. Our study also found that treatment of cells with ulinastatin along with docetaxel significantly inhibited uPA, uPAR and ERK1/2, leading to the maximum cell apoptosis rate among the three treatment groups (83.254\% at 72 hours)[6]. Therefore, the upregulation of these three proteins in response to docetaxel treatment should be considered as one of the drug-resistance mechanisms of MDA-MB-231 cells, and application of inhibitors (such as ulinastatin) can weaken this resistance.

This study revealed that uPA, uPAR and p-ERK expression is obviously inhibited by ulinastatin. Because many factors and mechanisms are involved in cancer cell proliferation, although treatment with ulinastatin alone can inhibit MDA-MB-231 cell proliferation and exograft growth[6], its effect is not as strong as that combined with docetaxel. On the other hand, although docetaxel enhanced the expression of uPA, UPAR and ERK1/2, its cell toxicity still plays a dominant role, so when treated with docetaxel alone, the proliferation and tumor growth of breast cancer cell was inhibited. Combined treatment of ulinastatin plus docetaxel is more effective in anti-tumor invasion. Therefore, the role of ulinastatin in the antitumor aspect deserves further study.

\section{Acknowledgements}

This work is supported by the Fund of Chongqing Science and Technology Commission (CSCT, 2008AC5082).

\section{Authors' contributions \\ \lrcorner did the cell invasion essay and immunohistochemistry, XS did the Cell- culturing, submitted paper and revised the paper, FG did the medical statistics, XZ cultured the cell and did PCR, BZ tested the cells in PCR, HW detected the cells in western blot, ZS designed this experiment and wrote this paper. All authors read and approved this final draft.}

Competing interests

The authors declare that they have no competing interests.

Received: 19 June 2011 Accepted: 29 July 2011 Published: 29 July 2011 


\section{References}

1. Stillfried GE, Saunders DN, Ranson M: Plasminogen binding and activation at the breast cancer cell surface: the integral role of urokinase activity. Breast Cancer Res 2007, 9(1):R14.

2. Nguyen DH, Hussaini IM, Gonias SL: Binding of urokinase-type plasminogen activator to its receptor in MCF-7 cells activates extracellular signal-regulated kinase 1 and 2 which is required for increased cellular motility. J Biol Chem 1998, 273(14):8502-8507.

3. Aguirre GJ, Kovalski K, Ossowski L: Tumor dormancy induced by downregulation of urokinase receptor in human carcinoma involves integrin and MAPK signaling. J Cell Biol 1999, 147(1):89-104.

4. Kobayashi H, Shinohara H, Takeuchi K, Itoh M, Fujie M, Saitoh M: Inhibition of the soluble and the tumor cell receptor-bound plasmin by urinary trypsin inhibitor and subsequent effects on tumor cell invasion and metastasis. Cancer Res 1994, 54(3):844-849.

5. Kobayashi H, Suzuki M, Tanaka Y, Hirashima Y, Terao T: Suppression of urokinase expression and invasiveness by urinary trypsin inhibitor is mediated through inhibition of protein kinase C- and MEK/ERK/C-Jundependent signaling pathways. J Biol Chem 2001, 276(3):2015-2022.

6. Zhao Xiaoliang, Sun Xin, Gao Feng, Luo Jie, Sun Zhijun: Effects of ulinastatin and docataxel on breast tumor growth and expression of IL6, IL-8, and TNF-a. Journal of Experimental \& Clinical Cancer Research 2011, 30:22.

7. Sun ZJ, YU T, Chen JS: Effects of Ulinastatin and Cyclophosphamide on the Growth of Xenograft Breast Cancer and Expression of CXCR4 and MMP-9 in Cancers. The Journal of International Medical Research 2010, 38:967-976.

8. Gao F, Sun ZJ: Progress in the correlation of vascular endothelial growth factor $\mathrm{C}$ and lymphangiogenesis and lymph node metastasis in breast cancer. Chongaing Medical Journal 2010, , 07: 819-821.

9. Mahanivong C, Yu J, Huang S: Elevated urokinase-specific surface receptor expression is maintained through its interaction with urokinase plasminogen activator. Mol Carcinog 2007, 46(3):165-175.

10. Sliva D, Rizzo MT, English D: Phosphatidylinositol 3-kinase and NF-kappaB regulate motility of invasive MDA-MB-231 human breast cancer cells by the secretion of urokinase-type plasminogen activator. J Biol Chem 2002, 277(5):3150-3157.

11. Kanse SM, Benzakour O, Kanthou C, Christine K, Roger Lijnen H, Preissner KT: Induction of vascular SMC proliferation by urokinase indicates a novel mechanism of action in vasoproliferative disorders. Arterioscler Thromb Vasc Biol 1997, 17(11):2848-2854.

12. Konakova M, Hucho F, Schleuning WD: Downstream targets of urokinasetype plasminogen-activator-mediated signal transduction. Eur $J$ Biochem 1998, 253(2):421-429.

13. Tang $H$, Kerins DM, Hao Q, Inagami T, Vaughan DE: The urokinase-type plasminogen activator receptor mediates tyrosine phosphorylation of focal adhesion proteins and activation of mitogen-activated protein kinase in cultured endothelial cells. J Biol Chem 1998, 273(29):18268-18272.

14. Webb DJ, Nguyen DH, Sankovic M, Gonias SL: The very low density lipoprotein receptor regulates urokinase receptor catabolism and breast cancer cell motility in vitro. J Biol Chem 1999, 274(11):7412-7420.

15. Webb DJ, Nguyen DH, Gonias SL: Extracellular signal-regulated kinase functions in the urokinase receptor-dependent pathway by which neutralization of low density lipoprotein receptor-related protein promotes fibrosarcoma cell migration and matrigel invasion. J Cell Sci 2000, 113(Pt 1):123-134.

16. Yu W, Kim J, Ossowski L: Reduction in surface urokinase receptor forces malignant cells into a protracted state of dormancy. J Cell Biol 1997, 137(3):767-777.

17. Seddighzadeh M, Zhou JN, Kronenwett U, Shoshan MC, Auer G, StenLinder $M$, et al: ERK signalling in metastatic human MDA-MB-231 breast carcinoma cells is adapted to obtain high urokinase expression and rapid cell proliferation. Clin Exp Metastasis 1999, 17(8):649-654.

18. Holst-Hansen C, Johannessen B, Hoyer-Hansen G, Romer J, Ellis V, Brunner N: Urokinase-type plasminogen activation in three human breast cancer cell lines correlates with their in vitro invasiveness. Clin Exp Metastasis 1996, 14(3):297-307.

19. Mhaidat NM, Thorne RF, Zhang XD, Hersey P: Regulation of docetaxelinduced apoptosis of human melanoma cells by different isoforms of protein kinase C. Mol Cancer Res 2007, 5(10):1073-1081.
20. Yacoub A, Han SI, Caron R, Gilfor D, Mooberry S, Grant S, et al: Sequence dependent exposure of mammary carcinoma cells to Docetaxel and the MEK1/2 inhibitor U0126 causes enhanced cell killing in vitro. Cancer Biol Ther 2003, 2(6):670-676.

21. Davies BR, Logie A, Mckay JS, Martin P, Steele S, Jenkins R, et al: AZD6244 (ARRY-142886), a potent inhibitor of mitogen-activated protein kinase/ extracellular signal-regulated kinase kinase $1 / 2$ kinases: mechanism of action in vivo, pharmacokinetic/pharmacodynamic relationship, and potential for combination in preclinical models. Mol Cancer Ther 2007, 6(8):2209-2219.

doi:10.1186/1756-9966-30-71

Cite this article as: Luo et al:: Effects of ulinastatin and docetaxel on breast cancer invasion and expression of UPA, UPAR and ERK. Journal of Experimental \& Clinical Cancer Research 2011 30:71.

\section{Submit your next manuscript to BioMed Central and take full advantage of:}

- Convenient online submission

- Thorough peer review

- No space constraints or color figure charges

- Immediate publication on acceptance

- Inclusion in PubMed, CAS, Scopus and Google Scholar

- Research which is freely available for redistribution

Submit your manuscript at www.biomedcentral.com/submit
C Biomed Central 